\title{
Effect of the Solution Temperature on the Precipitates and Grain Evolution of IN718 Fabricated by Laser Additive Manufacturing
}

\author{
Yu Cao ${ }^{1,2,3}$, Pucun Bai ${ }^{1, *}$, Fei Liu ${ }^{1}$, Xiaohu Hou ${ }^{1}$ and Yuhao Guo ${ }^{1}$ \\ 1 College of Materials Science and Engineering, Inner Mongolia University of Technology, Hohhot 010051, \\ China; ngdcaoyu@126.com (Y.C.); ngdliufei@163.com (F.L.); houxiaohuhu@163.com (X.H.); \\ gyh512480516@163.com (Y.G.) \\ 2 Department of Mechanical and Electrical Engineering, Hulunbiur College, Hulunbiur 021000, China \\ 3 Engineering Research Center for the Safe Exploitation and Comprehensive Utilization of Mineral Resources \\ at Universities of Inner Mongolia Autonomous Region, Hulunbiur 021000, China \\ * Correspondence: pcbai@imut.edu.cn; Tel.: +86-0471-6577053
}

Received: 15 December 2019; Accepted: 9 January 2020; Published: 11 January 2020

\begin{abstract}
The effects of the solution heat treatment temperature on the precipitates, grain boundary evolution and response of the microhardness of Inconel 718 (IN718) superalloy fabricated by selective laser melting (SLM) were investigated. It was found that: (1) The long-chained Laves phases formed in the as-deposited condition dissolved into the matrix when the solution temperature rises above $980^{\circ} \mathrm{C}$. (2) The width-to-length ratio was maintained at approximately 1.6 when the solution was heated from $980^{\circ} \mathrm{C}$ to $1080^{\circ} \mathrm{C}$, and dropped down to 1.03 when heated to $1130^{\circ} \mathrm{C}$. (3) Low-angle grain boundaries kept the same number fraction of $65 \%$ from 980 to $1080^{\circ} \mathrm{C}$ as the as-deposited condition, and decreased dramatically from 1090 to $1130{ }^{\circ} \mathrm{C}$ to $4 \%$. (4) Annealing twin boundaries occurred at $1090{ }^{\circ} \mathrm{C}$ with a number fraction of $3 \%$, and quickly increased to $65 \%$ when heated to $1130{ }^{\circ} \mathrm{C}$. It is concluded that the static recrystallization of IN718 fabricated by selective laser melting (SLM) occurred at $1090{ }^{\circ} \mathrm{C}$ and fast proceeded to full recrystallization at $1130{ }^{\circ} \mathrm{C}$. The forming of annealing twins accompanies the recrystallization process and is an effective way to refine the recrystallized grain size.
\end{abstract}

Keywords: SLM; IN718; precipitates; grain feature; recrystallization

\section{Introduction}

Inconel 718 (IN718) superalloy is mainly strengthened by precipitate of coherent, ordered metastable $\gamma^{\prime \prime}$ phase $\left(\mathrm{Ni}_{3} \mathrm{Nb}\right)$ with a body-centered tetragonal (bct) $\mathrm{DO}_{22}$ structure [1-3]. It has been widely used for hot section rotating components of gas turbines due to its excellent corrosion-resistant, thermal and strength properties under extreme working conditions. Selective laser melting is a promising additive manufacturing (AM) technique which can form metal parts with a complex shape and hollow structure directly [4-6]. The fast solidification rate of the selective laser melting (SLM) process can result in much finer microstructure and uniform element distribution. Thus, the macro segregation can be avoided, but micro segregation still exists during this process. Aiming to optimize the microstructure generated from SLM process, lots of researchers have investigated the heat treatment regime of SLMed parts [7-10]. The heat treatment regime of solution plus aging, which is similar with the forging IN718 parts, has been accepted by most researchers. However, most concerns are focused on the dissolution of detrimental precipitate generated from the SLM process and the precipitation of the strengthening phase $\gamma^{\prime \prime}$ during the aging process, and little attention has been paid to the grain boundary evolution during the solution heat treatment process. In fact, during the high 
temperature solution process, along with element homogenization, the grain boundary evolution is inevitable, which will also affect the mechanical properties of the parts. The presence of low-angle grain boundaries can produce strain strengthening, which will enhance the microhardness of the materials. In addition, Pande et al. [11] confirmed on the basis of experiments that annealing twin boundaries at room temperature can reduce the effective grain size and increase the room temperature yield strength of the alloy. Yuan et al. [12,13] found in a new type of Ni-Co based deformed superalloys that during the creep process of alloys, the annealed twin boundaries can hinder dislocation slippage and improve the high temperature creep life of alloy. Thus, investigation on the grain boundary evolution of this process is very meaningful. This research aims to explore the effect of the solution heat treatment temperature on both the precipitates and grain boundary migration and the response of the sample hardness, revealing the combined influence of precipitates and grain boundaries on the mechanical properties.

\section{Materials and Methods}

\subsection{SLM Experiment}

The chemical composition of gas atomized IN718 powder is revealed in Table 1. The SLM experiment was conducted on the EOS M280 rapid forming machine (EOS Gmbh, Munich, German). The material of substrate was 45 steel with dimensions of $250 \mathrm{~mm} \times 250 \mathrm{~mm} \times 30 \mathrm{~mm}$. In order to avoid deformation of the sample, the substrate was preheated to $80{ }^{\circ} \mathrm{C}$. The parameters of SLM process were as follows: $0.2 \mathrm{~mm}$ hatch spacing, $0.04 \mathrm{~mm}$ layer thickness, $350 \mathrm{~W}$ laser power, and $1000 \mathrm{~mm} / \mathrm{s}$ laser scanning speed, stripped scanning strategy shown in Figure $1 \mathrm{a}$, with $67^{\circ}$ turning angles layer by layer which have already been explored in our previous research [14]. As shown in Figure 1, the rectangular sample with dimensions of $10 \mathrm{~mm} \times 10 \mathrm{~mm} \times 100 \mathrm{~mm}$ was cut into 20 pieces to do the following heat treatment and microstructural observation.

Table 1. Chemical composition of Inconel 718 (IN718) powder (mass fraction: \%).

\begin{tabular}{cccccccc}
\hline Element & $\mathbf{A l}$ & $\mathbf{T i}$ & $\mathbf{C r}$ & $\mathbf{F e}$ & $\mathbf{N b}$ & $\mathbf{M o}$ & $\mathbf{N i}$ \\
\hline $\mathrm{wt} \%$ & 0.6 & 1.0 & 19.7 & 18.4 & 5.1 & 3.0 & Bal. \\
\hline
\end{tabular}

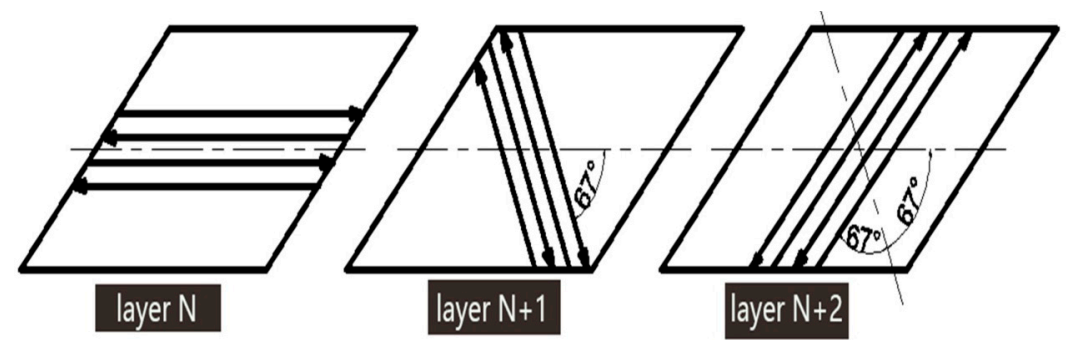

(a)

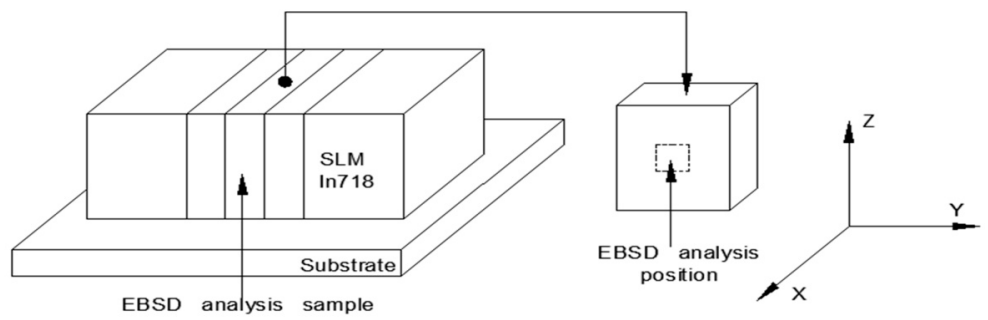

(b)

Figure 1. (a) Scanning strategy sketch map. (b) Sketch map of sample cutting and electron backscatter diffraction (EBSD) analysis sections ( $Z$ direction is the building direction). 


\subsection{Heat Treatment}

Different solution heat treatments parameters are illustrated in Table 2. Solution heat treatments were conducted between $930^{\circ} \mathrm{C}$ and $1230^{\circ} \mathrm{C}$ for $1 \mathrm{~h}$, after which the samples were quenched in the water to room temperature (WC). All the solution heat treatment procedures were performed in a KSL-1400X furnace (MTI Corporation, Shenyang, China).

Table 2. Solution heat treatment process parameters.

\begin{tabular}{cccc}
\hline Designation & Solution Treatment & Designation & Solution Treatment \\
\hline As-deposited & $\times$ & $\mathrm{H} 1090$ & $1090^{\circ} \mathrm{C} / \mathrm{h} / \mathrm{WC}$ \\
$\mathrm{H} 930$ & $930^{\circ} \mathrm{C} / \mathrm{h} / \mathrm{WC}$ & $\mathrm{H} 1100$ & $1100^{\circ} \mathrm{C} / \mathrm{h} / \mathrm{WC}$ \\
$\mathrm{H} 980$ & $980^{\circ} \mathrm{C} / \mathrm{h} / \mathrm{WC}$ & $\mathrm{H} 1110$ & $1110^{\circ} \mathrm{C} / \mathrm{h} / \mathrm{WC}$ \\
$\mathrm{H} 1030$ & $1030^{\circ} \mathrm{C} / \mathrm{h} / \mathrm{WC}$ & $\mathrm{H} 1120$ & $1120^{\circ} \mathrm{C} / \mathrm{h} / \mathrm{WC}$ \\
$\mathrm{H} 1080$ & $1080^{\circ} \mathrm{C} / \mathrm{h} / \mathrm{WC}$ & $\mathrm{H} 1130$ & $1130^{\circ} \mathrm{C} / \mathrm{h} / \mathrm{WC}$ \\
\hline
\end{tabular}

\subsection{Microstructural Investigation}

Scanning electron microscopy (SEM) (Quanta 650, FEI, Hillsboro, OR, USA) was used to observed the microstructure and precipitate distribution, operating at $20 \mathrm{kV}$ and equipped with a secondary electron signal for imaging. For electron backscatter diffraction (EBSD) observation, the specimens were mechanically polished, followed by electropolishing in a solution of $10 \%$ perchloric acid and $90 \%$ ethanol at $25 \mathrm{~V}$ for $30 \mathrm{~s}$ to produce a strain-free surface. EBSD measurement was performed with the following parameters: a spot size of 6.0 , accelerating voltage $20 \mathrm{kV}$, and step size of $1.2 \mu \mathrm{m}$. Microstructure analyses were carried out using a fully automated EBSD system with KHL channel 5 software (5.0, Oxford Instruments, Abingdon, Oxfordshire, UK). The misorientation angles (MAs) less than $2^{\circ}$ were deleted to eliminate the false boundaries caused by the orientation noise. The MAs between $2^{\circ}$ and $10^{\circ}$ were defined as low-angle boundaries (LABs), and the MAs above $10^{\circ}$ defined as high-angle boundaries (HABs). The kernel average misorientation angles (KAMAs) below $1^{\circ}$ (low KAMAs) denoted the low local misorientation versus the high ones, compared with KAMAs above $1^{\circ}$ (high KAMAs). Thin foils with a diameter of $3 \mathrm{~mm}$ for transmission electron microscopy (TEM) were prepared by mechanically grinding down to $50 \mu \mathrm{m}$ and further electropolishing down to electron transparency. The TEM characterization was performed using a TEM (Talos 200, FEI, Hillsboro, OR, USA), operating at an accelerating voltage of $200 \mathrm{kV}$ to make the crystal structure determination.

\subsection{Microhardness Test}

The hardness measurement of the samples of different conditions was performed by a hardness testing device (HVS-30, Shanghai Gaozhi Precision Instrument Co., Ltd., Shanghai, China) under a load of $0.98 \mathrm{~N}$ for a dwell time of $15 \mathrm{~s}$ with an interval of $0.1 \mathrm{~mm}$.

\section{Results and Discussion}

\subsection{Precipitates}

During the SLM process, micro segregation is easy to form because of the high solidification rate and small laser spot size of SLM process [15]. Niobium $(\mathrm{Nb})$ is easy to be trapped in the liquid phase during the solidification process due to the lower value of the partition coefficient [16]. Thus, Laves phases enriched of $\mathrm{Nb}$ have always been observed in the as-deposited IN718. Laves phases have been proved to be detrimental to the mechanical properties of SLMed IN718 by many researchers [17,18]. In addition, Laves phase has exhausted much $\mathrm{Nb}$ which is used to form the strengthening phase $\gamma^{\prime \prime}$ $\left(\mathrm{Ni}_{3} \mathrm{Nb}\right)$ in the following aging treatment process. Trying to release $\mathrm{Nb}$ into the matrix during the solution heat treatment process is essential to improve the property of SLMed IN718.

Figure 2 shows the precipitate distributions of IN718 samples in the as-deposited condition and different solution heat treatment conditions. In Figure 2a, the Laves phase distributed along the grain 
boundaries and subgrain boundaries to form a chained-like connection, which has clearly displayed the grain boundaries and dendrite-cellular substructure inside of the grains. The forming of the finer substructures was attributed to the high cooling rate. Figure $2 b$ illustrates more precipitates with profuse morphologies. The acicular precipitates were coarse $\gamma^{\prime \prime}$ and the short-rod precipitate was $\delta$ $\left(\mathrm{Ni}_{3} \mathrm{Nb}\right)$, which is in accordance to the references $[19,20]$. Under the solution heat treatment condition of $930^{\circ} \mathrm{C} / \mathrm{h}, \delta$ phase precipitates from the matrix, since the precipitation temperature of $\delta$ is between $750{ }^{\circ} \mathrm{C}$ and $950{ }^{\circ} \mathrm{C}$ in IN718. As the equilibrium phase of $\gamma^{\prime \prime}, \delta$ phase has proven to be detrimental to the high-temperature property of IN718. However, moderate $\delta$ could inhabit the migration of the grain boundaries to maintain the grain size [21]. When the solution temperature increased to $980{ }^{\circ} \mathrm{C}$, most of the Laves phases have dissolved into the matrix and regular arranged short-rod $\delta$ was observed along the grain boundaries. From $1030{ }^{\circ} \mathrm{C}$ to $1230{ }^{\circ} \mathrm{C}$, the distribution of precipitates showed almost the same condition. A small amount of undissolved particle Laves phases were found along the subgrain boundaries and undissolved bulk Laves phases were found along the grain boundaries. This is mainly because in the as-deposited condition, the grain boundaries accumulated more Laves phases than the subgrain boundaries with bigger dimension and higher concentration of $\mathrm{Nb}$. During this temperature interval from $1030{ }^{\circ} \mathrm{C}$ to $1230{ }^{\circ} \mathrm{C}$, with the rising of the temperature, the morphology of the Laves phase distribution is basically unchanged. Even the higher solution temperature could not dissolve all the Laves phases. To be noted, incipient melting phenomenon has been found in the $1280{ }^{\circ} \mathrm{C}$ solution condition, as indicated in Figure $2 \mathrm{~h}$. According to the reference [22-24], eutectic reaction of Laves phase occurs at $1160-1200{ }^{\circ} \mathrm{C}$ and the solidus temperature of Laves phase is $1255^{\circ} \mathrm{C}$. In fact, $1180^{\circ} \mathrm{C}$ is the critical temperature to occur the incipient melting of Laves phases in the wrought IN718. However, the incipient melting did not occur until $1230^{\circ} \mathrm{C}$ in the SLMed IN718. During the SLM process, the solidification rate is so high that the demission of the Laves phase is much smaller than in the conventional forging process, which means it is easier to dissolve the Laves phase generated from the SLM process than in the conventional forging process. Thus, the incipient melting occurs above the solidus temperature of Laves phase in the SLM process.
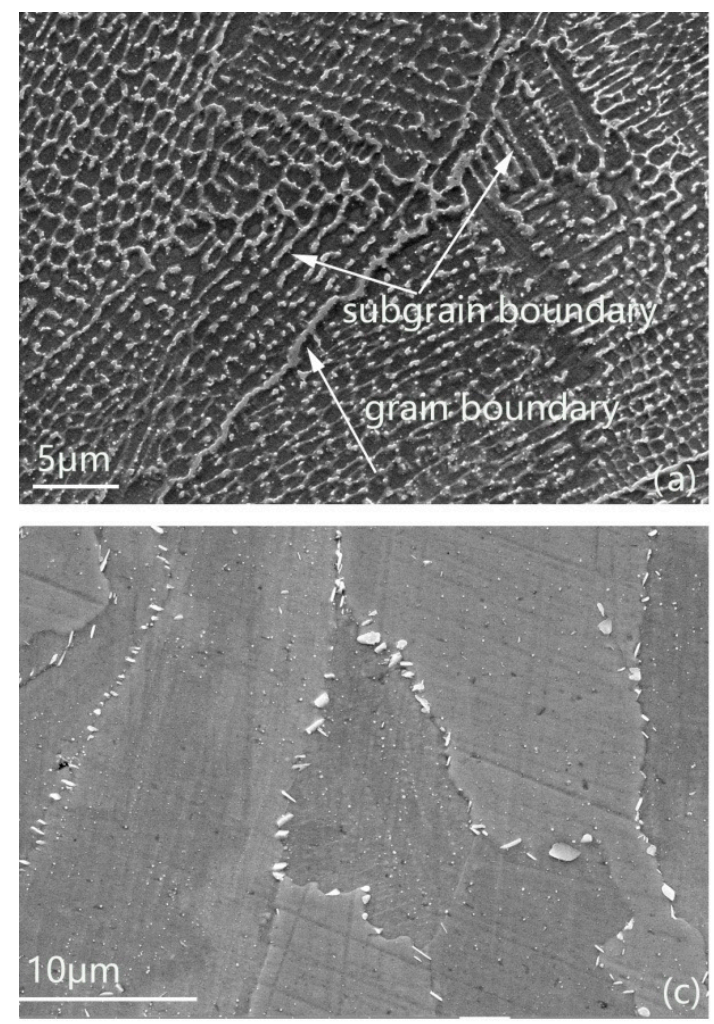
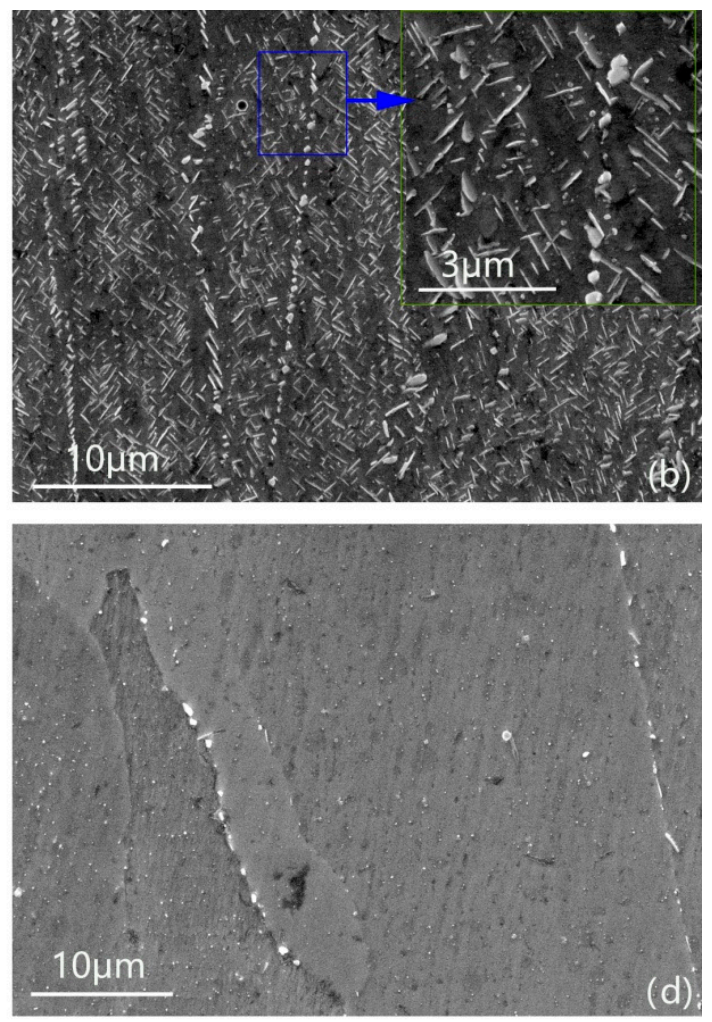

Figure 2. Cont. 

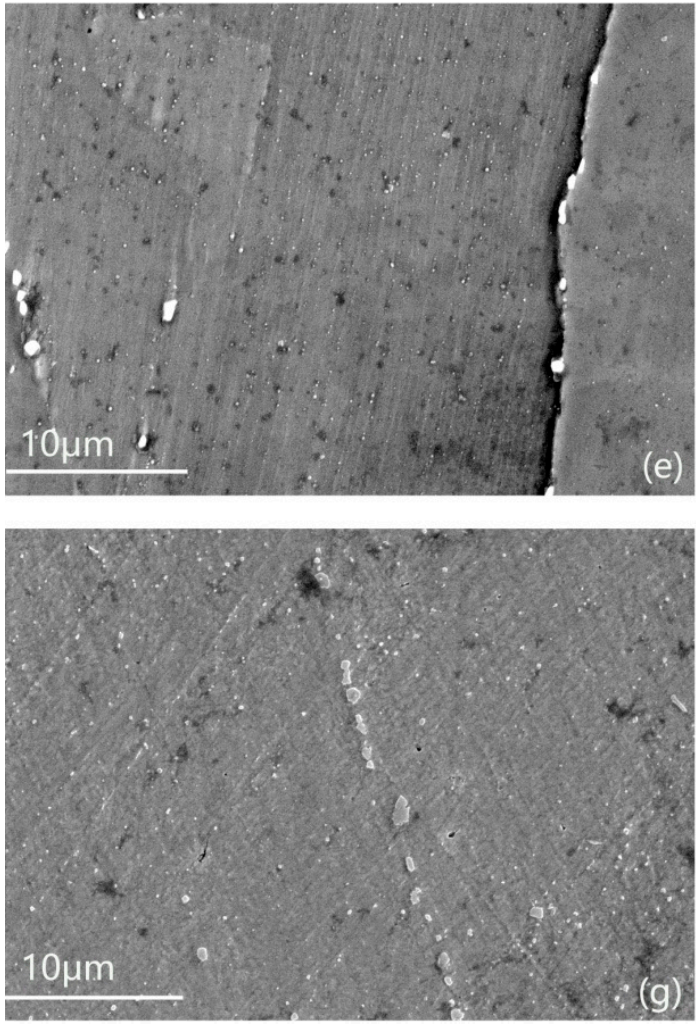
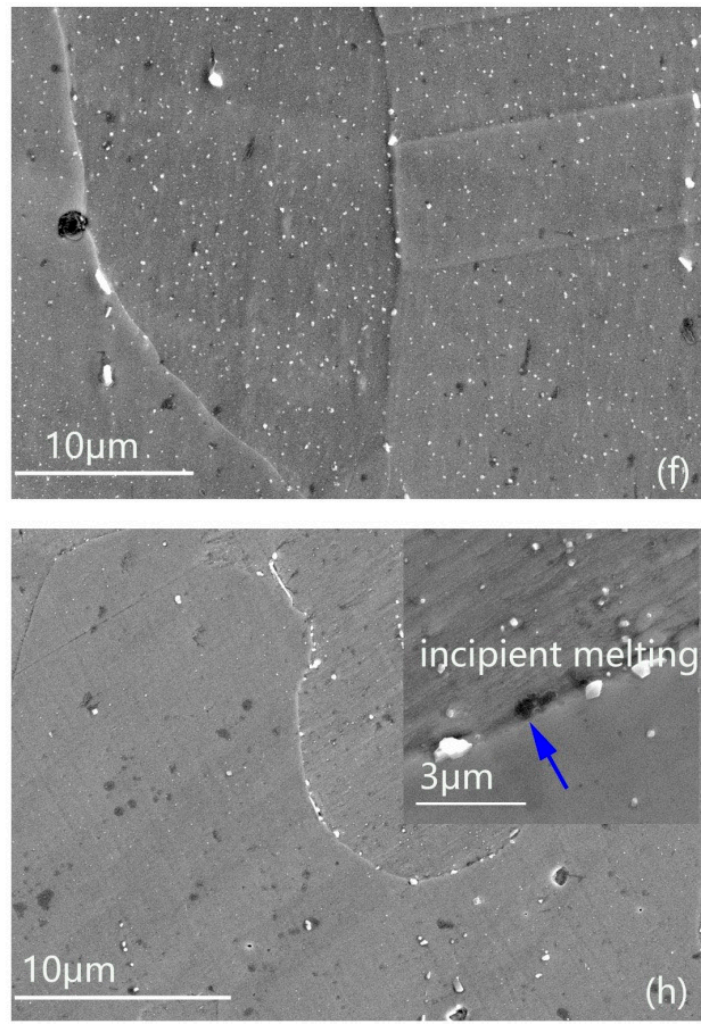

Figure 2. Precipitates distributions of as-deposited sample and solution-treated samples at different temperatures: (a) As-deposited, (b) $930{ }^{\circ} \mathrm{C}$, (c) $980{ }^{\circ} \mathrm{C}$, (d) $1030{ }^{\circ} \mathrm{C},(\mathbf{e}) 1080{ }^{\circ} \mathrm{C}$, (f) $1130{ }^{\circ} \mathrm{C},(\mathrm{g}) 1180{ }^{\circ} \mathrm{C}$, (h) $1230{ }^{\circ} \mathrm{C}$.

\subsection{Grain Features}

Though the solution heat treatment can homogenize the element distribution of the sample, the static recrystallization phenomenon triggered by the solution heat treatment also can affect the microstructure and the mechanical properties of the samples. During the SLM process, each layer has experienced heating and cooling repeatedly, resulting in the residual stress in the samples [25]. The residual stress is employed as the driving force in the following solution heat treatment process to trigger the static recrystallization at the appropriate temperature and time [26]. Different from conventional forging and extruding processes, the samples fabricated by the SLM process haven't experienced the big plastic deformation, and the deformation energy storage is relatively low. The grain size and grain distribution have special features after static recrystallization.

\subsubsection{Grain Size}

Figure 3 is the inverse-pole figure map of the samples in the as-deposited and different solution heat treatment conditions. A color-coded triangle is displayed in the top right corner. In Figure 3a, the microstructure of the as-deposited sample is composed of a significant number of elongated columnar grains and small quantity of equiaxed grains. Since most of the grains are columnar grains, the average grain width along $X$ axis direction and average grain length along $Z$ axis direction were measured to characterize the grain size features by the linear intercept method. The average grain width was about $9.09 \mu \mathrm{m}$ and grain length was $15.11 \mu \mathrm{m}$, and the aspect ratio (length to width ration) was about 1.66 of the as-deposited condition. In the SLM process, the heat dissipation direction is almost along the building direction, so most of the grains epitaxially grow along same direction with little tilting angles to form the columnar grains. The maximum length of columnar reached approximately $200 \mu \mathrm{m}$, which means the grain was epitaxially grown across $6-7$ layers. In Figure $3 b-d$, it is difficult to distinguish the 
recrystallization nucleus and initial small equiaxed grains of as-deposited condition. It is ambiguous whether the recrystallization process occurred. From $1080^{\circ} \mathrm{C}$ to $1130^{\circ} \mathrm{C}$, the $50^{\circ} \mathrm{C}$ temperature interval proceeded the recrystallization process quickly. In order to see the detailed transformation, the results of grain evolution of heat solution treatment conditions of $1080^{\circ} \mathrm{C} / \mathrm{h}$ to $1130^{\circ} \mathrm{C} / \mathrm{h}$ with $10^{\circ} \mathrm{C}$ intervals are illustrated in Figure 4. Figure 5 reveals the aspect ratio of the samples in different solution treatment conditions. From $980-1080^{\circ} \mathrm{C}$, the aspect ratio showed no obvious change, holding on around 1.6. Under the solution heat treatment condition of $1130^{\circ} \mathrm{C} / \mathrm{h}$ in Figure 3e, the grain width became bigger and grain morphology changed into equiaxed grain, while the aspect ratio decreased to 1.03, which means complete recrystallization finished. To be noted, some annealing twins in the interior of the grains have also been observed under this condition.
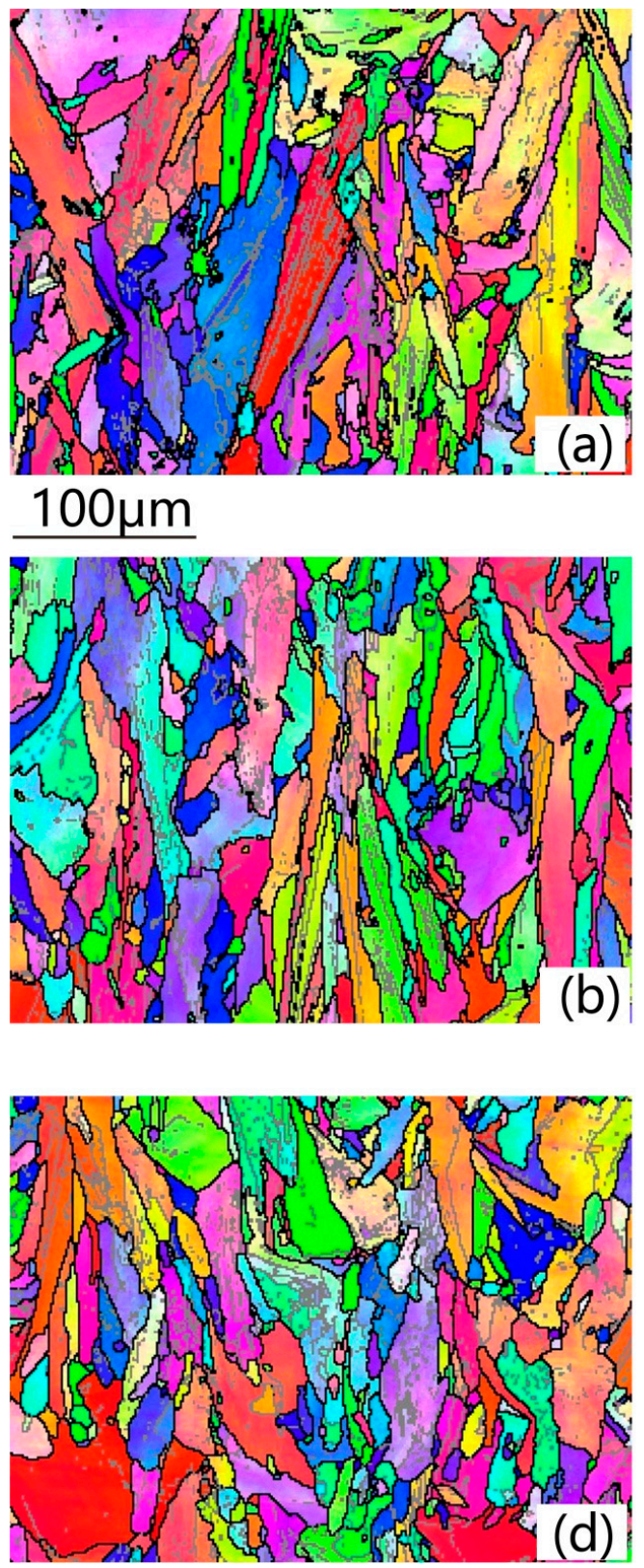
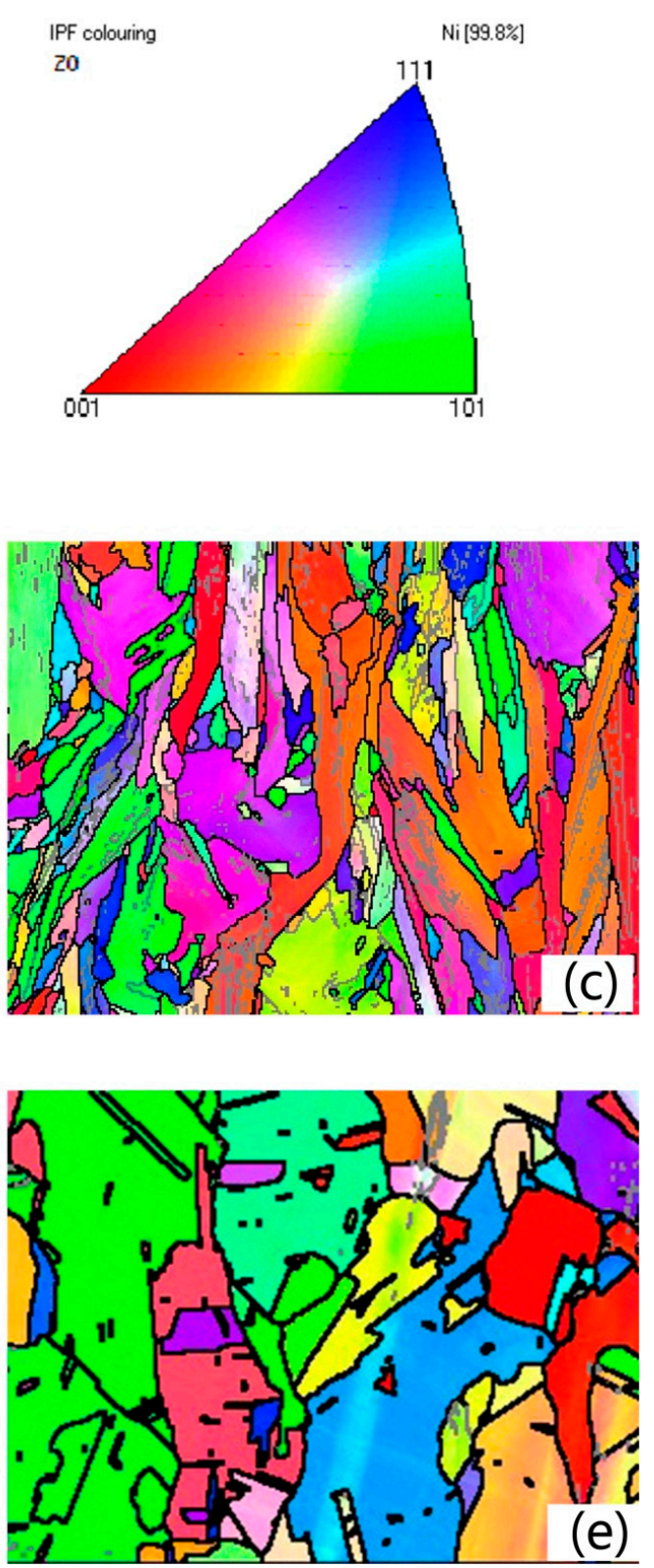

Figure 3. EBSD inverse-pole figure of the samples: (a) As-deposited condition, (b) $980{ }^{\circ} \mathrm{C} / \mathrm{h},(\mathbf{c}) 1030^{\circ} \mathrm{C} / \mathrm{h}$, (d) $1080^{\circ} \mathrm{C} / \mathrm{h},(\mathbf{e}) 1130{ }^{\circ} \mathrm{C} / \mathrm{h}$. 

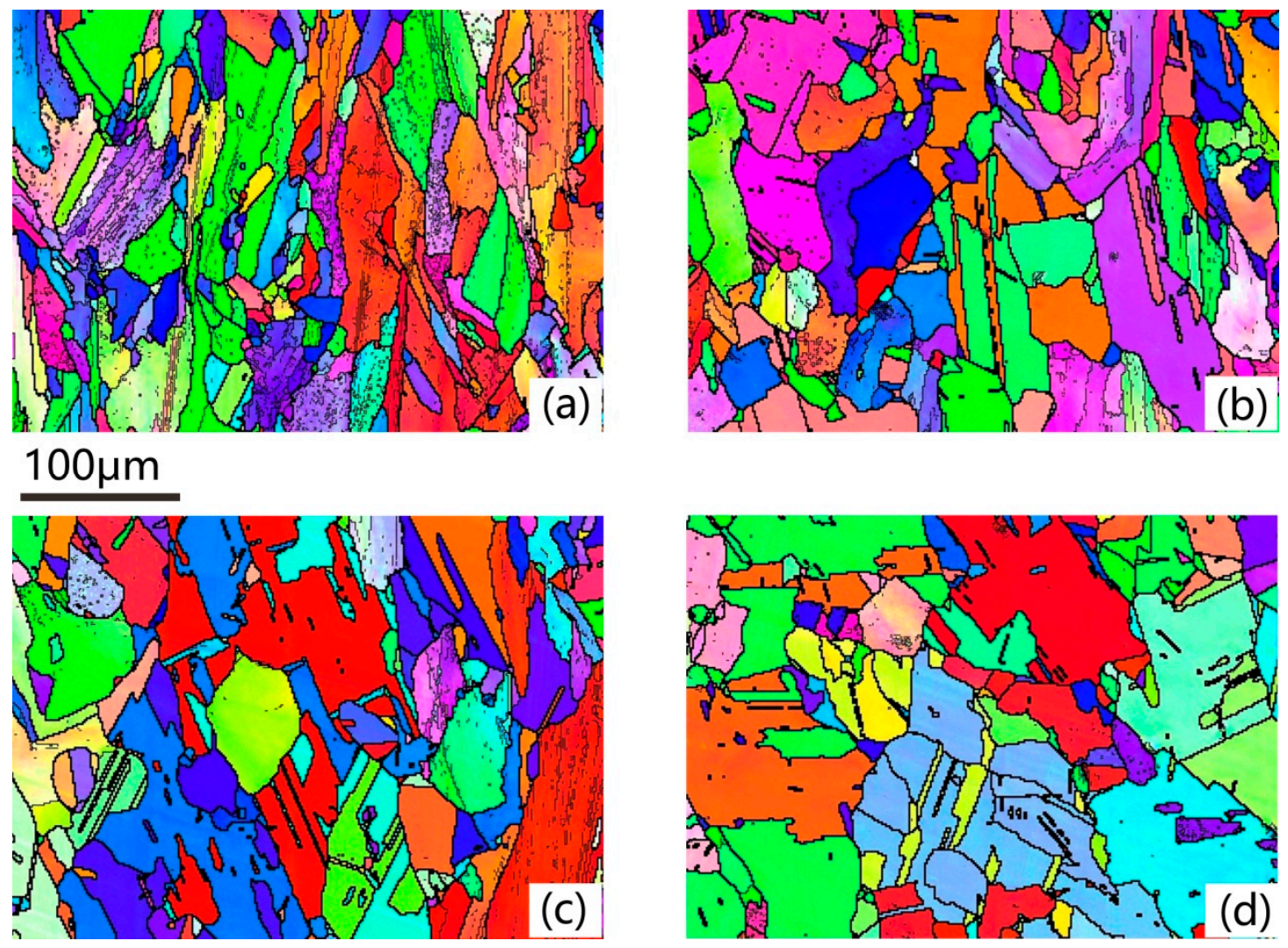

Figure 4. EBSD inverse-pole figure of the samples, (a) $1090{ }^{\circ} \mathrm{C} / \mathrm{h}$, (b) $1100{ }^{\circ} \mathrm{C} / \mathrm{h}$, (c) $1110{ }^{\circ} \mathrm{C} / \mathrm{h}$, (d) $1120^{\circ} \mathrm{C} / \mathrm{h}$.

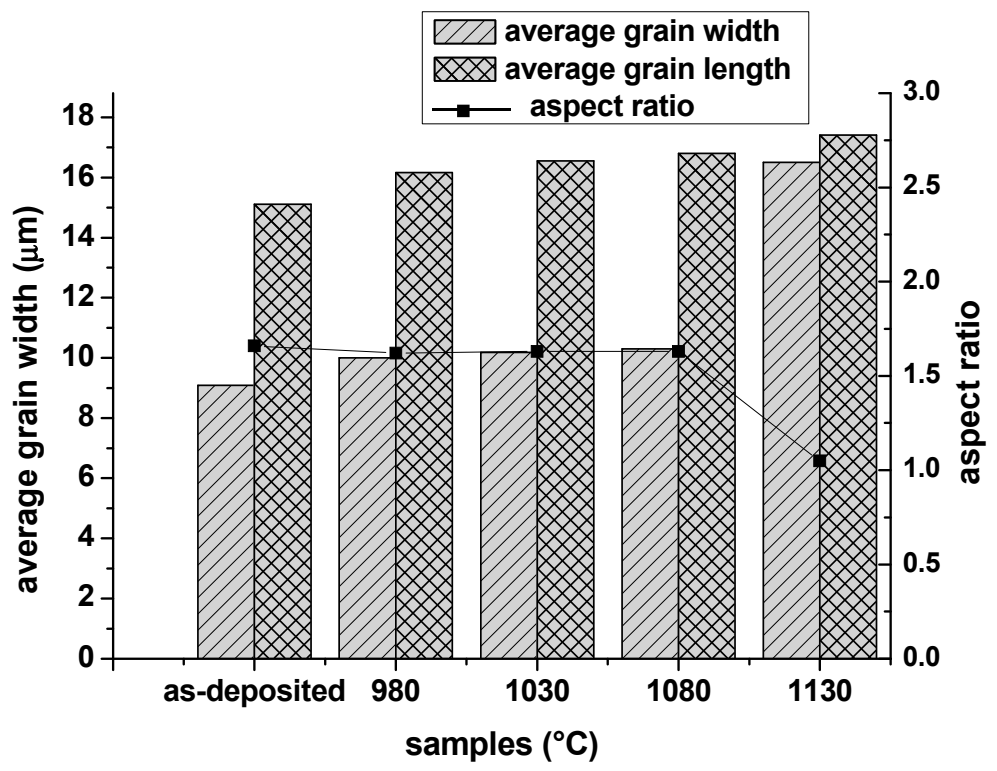

Figure 5. Average grain width, average grain length and grain width-length ratio of samples in different solution heat treatment conditions. 
Figure 4a shows almost the same condition with Figure 3d; the mix grains occupied the whole section. Even some recrystallization nucleuses accumulated along the grain boundaries of the columnar grains, but some un-recrystallized coarse columnar grains with some substructures in them were dominant of this condition. When heated to $1110^{\circ} \mathrm{C}$, distinct changes occurred: fully recrystallized grains with annealing twins inside and un-recrystallized columnar grains with substructures coexisted in the grain morphology. Due to the uneven grain distribution in the as-deposited condition, the stored energy which is the driving force of recrystallization process was not homogeneous. Thus, the extent of recrystallization was different in different areas. When heated to $1120^{\circ} \mathrm{C}$, more recrystallized grains and less deformed grains showed on this section. The full recrystallized grains with annealing twins became the only grain morphology at $1130{ }^{\circ} \mathrm{C}$. The annealing twins only existed in the unstrained recrystallized grain, which means the recrystallization process is accompanied by the formation of twins. It is a vital way to refine the grain size during the recrystallization process.

The deformation amount can affect the recrystallization temperature is one aspect. The bigger the deformation is, the more energy storage, and the bigger the driving force of the recrystallization process. Thus, a lower recrystallization temperature is needed. However, during the SLM process, deformation is much smaller, which leads to higher recrystallization temperature. The visible recrystallization process occurred in $1090^{\circ} \mathrm{C}$. In addition, the precipitates concentrated along the grain boundaries and subgrain boundaries can also inhabit the grain migration and the movement of the dislocation. During $980-1080{ }^{\circ} \mathrm{C}$, even most of the Laves phases were dissolved into the matrix. There were still some undissolved small particles distributed along the grain boundaries and subgrain boundaries, which inhabited the migration of the grain boundaries. As a result, the recrystallization temperature is raised. Finally, the initial grain sizes of the as-deposited condition were big compared to the traditional forging process, and the total area per unit volume was small. Thus, less recrystallization nucleation sites were available.

\subsubsection{Misorientation Angle Evolution}

Figure 3 also shows the distribution of the LABs and HABs, which are represented by the gray full lines and black full lines, respectively.

Figure 3 a indicates the columnar grains with relatively high density of LABs, which is in accordance with microstructure in Figure 2a. During the solidification process of SLM, the substructure of the grain is composed of columnar dendrites and cellular dendrites which are divided by the LABs. From $980^{\circ} \mathrm{C}$ to $1080^{\circ} \mathrm{C}$, the LABs in the columnar grains maintained the same status. When heated to $1130^{\circ} \mathrm{C}$, the LABs decreased significantly and most of HABs were twin boundaries. Figure 6 shows the number fraction (NF) of LABs, HABs and annealing twins' boundaries of different heat treatment statuses. The NF of the LABs in as-deposited condition and $980^{\circ} \mathrm{C} / 1030^{\circ} \mathrm{C} / 1080^{\circ} \mathrm{C}$ fluctuated around $34 \%$ with small deviation. After $1090^{\circ} \mathrm{C}$, the LABs began to decrease while the NF of the HABs increased. The NF of annealing twins showed the same trends with the HABs. After $1120^{\circ} \mathrm{C}$, the NF of annealing twins was stable at $60 \%$. This result indicates that the recovery process didn't occur during 980-1080 ${ }^{\circ} \mathrm{C}$, and after $1090^{\circ} \mathrm{C}$ the recrystallization process emerged. 


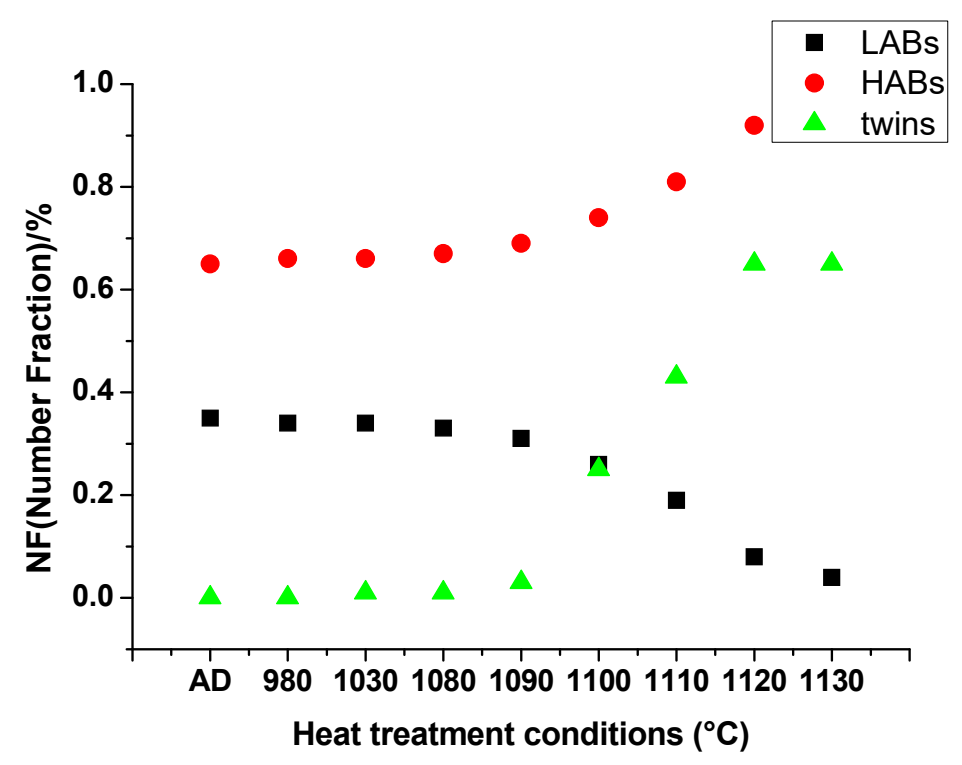

Figure 6. Grain boundary distributions of as-deposited condition and different solution heat treatment conditions.

IN718 is a kind of alloy with medium or low stacking fault energy. For metals with low and medium layer fault energy, the softening mechanism is mainly recrystallization, not recovery [27]. When the stacking fault energy is low, the total dislocation can be easily decomposed into an extended dislocation with a large stack fault width. The recovery process mainly relies on dislocations to offset the dislocations of each other after climbing, slipping or cross-slipping. The process of reducing the dislocation density is manifested by the reduction of LABs. It is very hard for the extended dislocations to climb, slip or cross-slip, because the extended dislocations contain staking faults. If so, the reverse process of the total dislocation decomposition called bundle is needed. However, the lower the stacking fault energy, the wider the extend dislocation, and the more difficult the bundle. Thus, it is difficult to recover.

Figure 7 gives the KAMA map of samples of different solution treatment conditions to estimate the plastic strain. The color-coded bars are shown in the top left corner of Figure 7a. KAMAs reveal the local variation of lattice orientation in a given area defined by the investigators, and it is a good indicator of plastic strains in crystals [28-31]. Figure 7 suggests that the higher value of KAMAs mainly focused on the columnar grains with lots of LABs in them. As the arrangements of dislocations, the LABs can be roughly associated with the plastic strains. Figure $7 \mathrm{~b}$ shows the number fraction (NF) of the KAMAs on the as-deposited condition. The low KAMAs donated $56 \%$. This existing internal stress can motivate recrystallization nucleation when proper solution temperature is provided. Figure 7a-e indicates that with the increase of solution temperature, the distribution change of KAMAs was not obvious; this result is quantitatively counted in Figure 8. The NF of low KAMAs of heat-treated conditions was little higher than that of the as-deposited condition, but was still less than 0.65 . Figure $7 \mathrm{f}$ shows the uniform distribution of the KAMAs until heated to $1130^{\circ} \mathrm{C}$, since the sample was totally recrystallized under this condition. After recrystallization, the unstrained equiaxed grains replaced the columnar grains. The residual stress was totally released. To make the detailed description of the recrystallization process, the KAMAs distribution from $1090-1120^{\circ} \mathrm{C}$ is given in Figure 9 . Figure 10 shows the NF of the low KAMAs from $1090^{\circ} \mathrm{C}$ to $1120^{\circ} \mathrm{C}$. The NF of the low KAMAs increased from 0.52 to 0.92 , indicating the residual stress gradually decreased. 

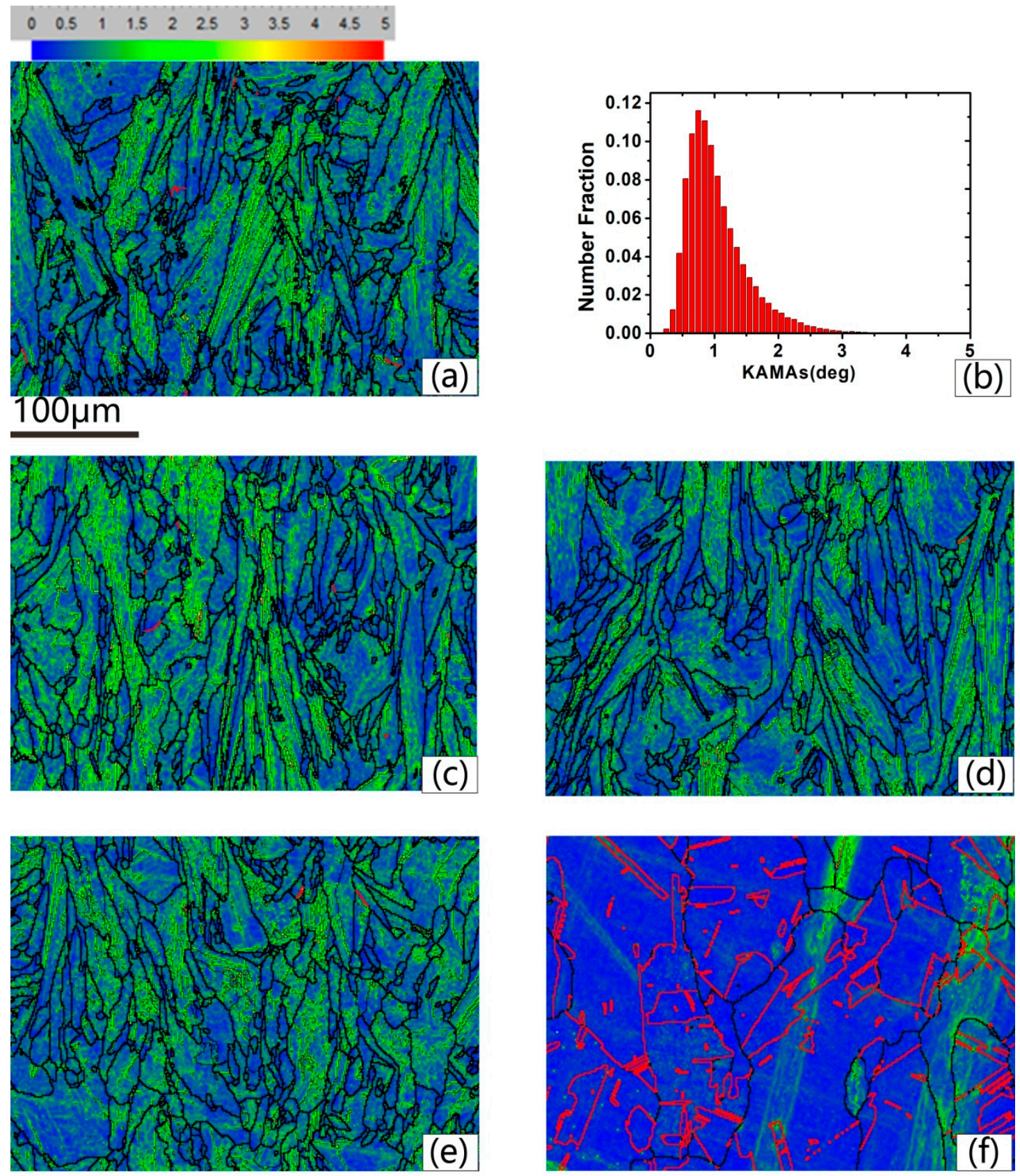

Figure 7. Kernel average misorientation angles (KAMAs) distribution and $<111>60^{\circ}$ annealing twins boundaries distribution under different conditions: (a) As-deposited condition, (b) number fraction (NF) of KAMAs under as-deposited condition, (c) $980{ }^{\circ} \mathrm{C}$, (d) $1030{ }^{\circ} \mathrm{C},(\mathbf{e}) 1080^{\circ} \mathrm{C},(\mathbf{f}) 1130{ }^{\circ} \mathrm{C}$. 


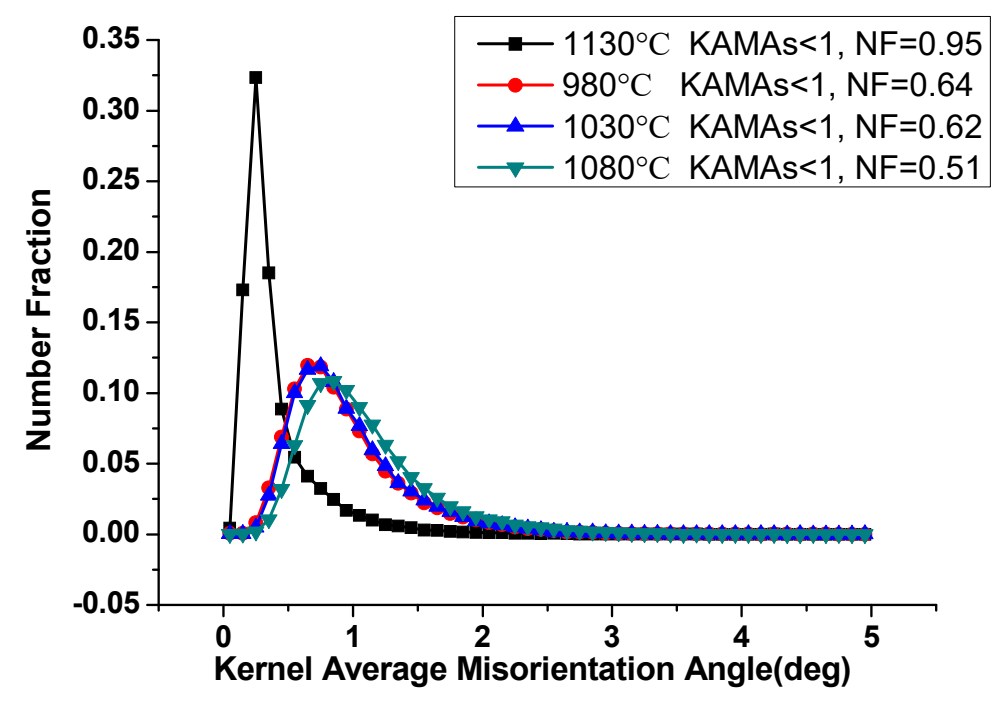

Figure 8. NF of KAMAs of $980{ }^{\circ} \mathrm{C} / 1030{ }^{\circ} \mathrm{C} / 1080{ }^{\circ} \mathrm{C} / 1130{ }^{\circ} \mathrm{C}$.
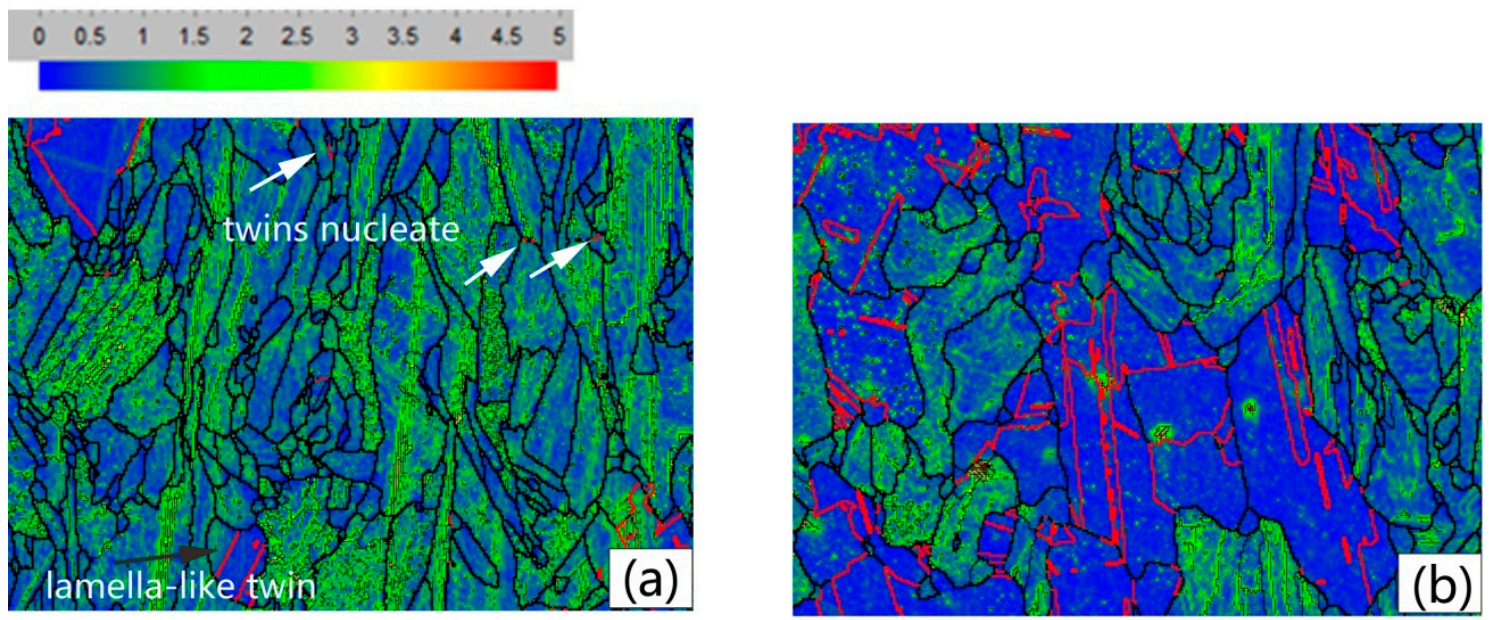

\section{$100 \mu \mathrm{m}$}
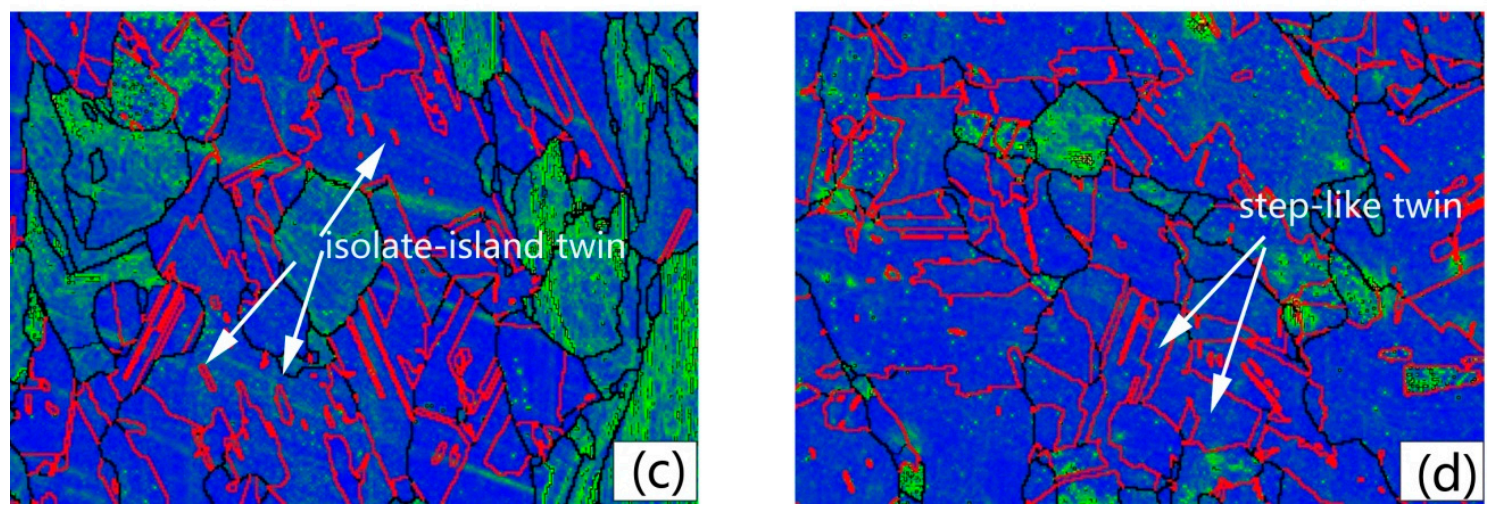

Figure 9. KAMAs distribution and $<111>60^{\circ}$ annealing twins boundaries distribution under different conditions: (a) $1090^{\circ} \mathrm{C}$, (b) $1100{ }^{\circ} \mathrm{C}$, (c) $1110{ }^{\circ} \mathrm{C}$, (d) $1120^{\circ} \mathrm{C}$. 


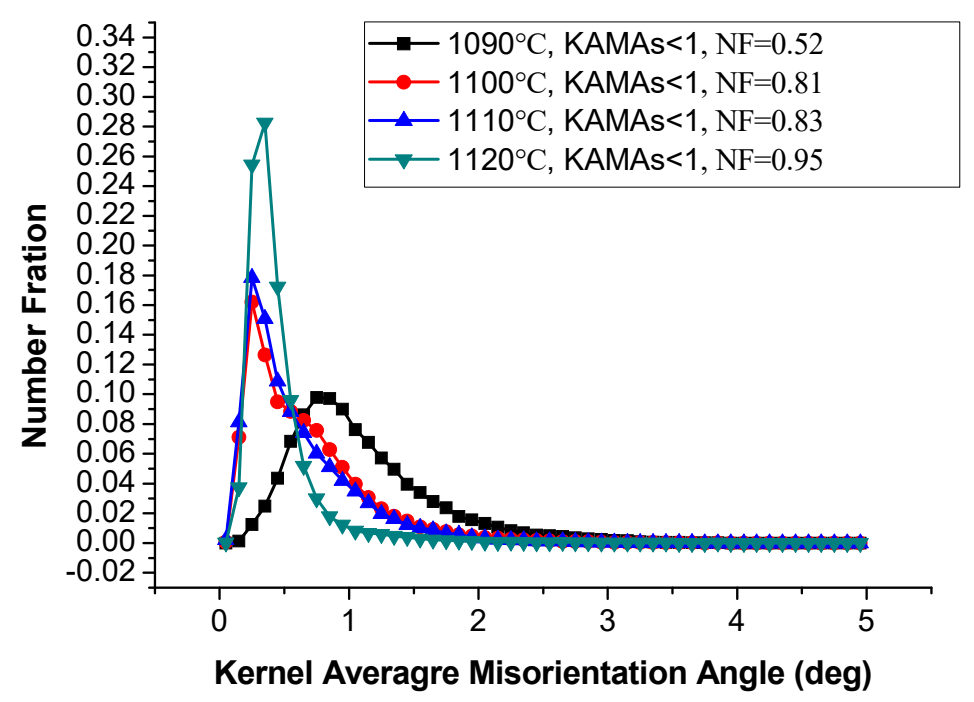

Figure 10. NF of KAMAs of $1090^{\circ} \mathrm{C} / 1100{ }^{\circ} \mathrm{C} / 1110{ }^{\circ} \mathrm{C} / 1120^{\circ} \mathrm{C}$.

\subsubsection{Annealing Twins}

Figure 9a shows the lamella-like straight $<111>60^{\circ}$ annealing twins in the recrystallized grains. The annealing twin boundary is represented by red full lines. Some annealing twins nucleated on the trigeminal grain boundaries, shown by the white arrows. With the growth of the recrystallized grains, the annealing twin extended to the grain boundary. From $980{ }^{\circ} \mathrm{C}$ to $1080^{\circ} \mathrm{C}$, the $\mathrm{NF}$ of the annealing twin boundary held on $1 \%$, which means the forming of annealing twins is accompanied with grain growth process of recrystallization instead of recovery. With the increasing of solution temperature from $1090{ }^{\circ} \mathrm{C}$ to $1130{ }^{\circ} \mathrm{C}$, the NF of annealing twins boundary dramatically increased from $3 \%$ to $65 \%$ as illustrated in Figure 6 . On the one hand, the rising of temperature can increase the amount of recrystallization grains. On the other hand, the higher the temperature is, the bigger the grain size is. Bigger grain size can enhance the amount of annealing twins. When heated to $1110{ }^{\circ} \mathrm{C}$, another annealing morphology appeared. The isolate-island-like annealing twins indicated by the white arrows in Figure $9 \mathrm{c}$ were isolated inside of the grain, not connecting to the grain boundary. Figure $9 \mathrm{~d}$ demonstrates the annealing twin distribution of $1130{ }^{\circ} \mathrm{C}$. Most of the annealing twins connected with grain boundaries, while few step-like twins appeared under this temperature. The annealing twin boundaries became more and longer. Thus, the annealing twin boundaries connected with each other or with the grain boundaries to form a seal grain, which has refined the grain size of the recrystallized grains. The twins that were mainly present in the forged IN718 alloy were deformed twins. A large number of deformed twins were observed in the initial structure before the annealing process. According to [32], the $<111>60^{\circ}$ twin in the original microstructure took $13.35 \%$. After the heat treatment process, the main annealing twin morphology was lamella-like annealing twins.

A large number of twins will appear in the face-centered-cubic structured alloys with medium or low stacking fault energy like IN718 during the solution heat treatment process. The interface energy of annealing twin is $1 / 10^{\text {th }}$ of that of HABs [33], which means excellent grain boundary stability. Thus, the driving force of forming annealing twins is the decreasing of grain boundary energy. Gleiter [34] and Mahajan [35] have done lots of research on the forming mechanism of annealing twins. The "growth accident" mechanism has been fully accepted to explain the forming of the lamella-like straight annealing twins. Firstly, the annealing twins boundaries originates from the trigeminal grain boundary, where the interface energy is relatively high. With the grain growth, the crystal planes which are parallel to the $\{111\}$ atomic planes are proned to occure the atomic misarrangement, forming stacking faults. The stacking faults enhance the system free energy. In order to reduce the free energy of the system, the subsequent order of atomic stacking on the $\{111\}$ atomic plane requires stacking in a mirror-symmetrical manner with the fault to improve the symmetry of the system. That is, twin 
boundaries are formed during $\{111\}$ atomic plane migration. Figure 11 a reveals the stacking faults observed by TEM under the as-deposited condition. The stacking faults have proved the possibility of the "growth accidents" mechanism.
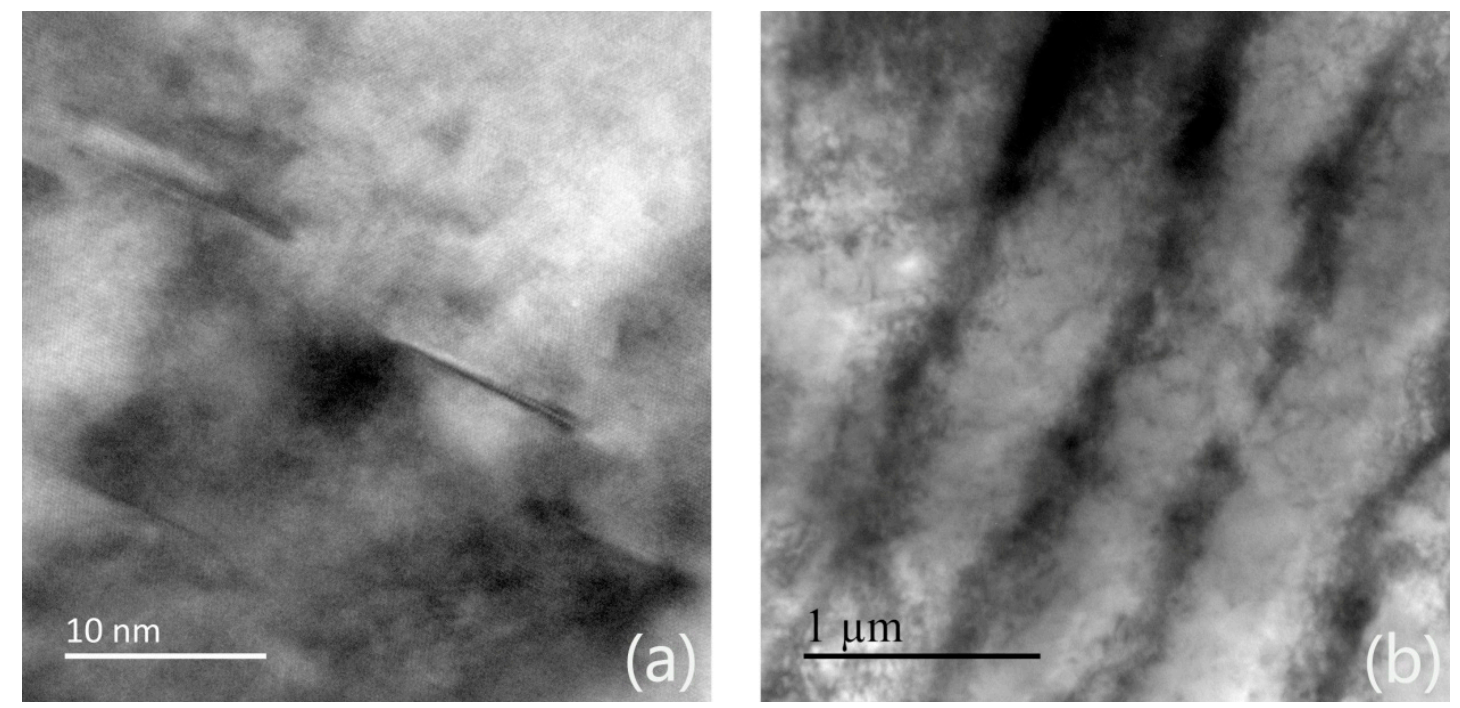

Figure 11. (a) TEM observation of the stacking faults in the as-deposited condition; (b) dislocations in the as-deposited condition.

\subsection{Microhardness}

The microhardness of the sample in different heat treatment conditions is presented in Figure 12. The strengthening mechanisms are ascribed to the substructure strengthening and precipitate strengthening mechanism. According to the substructure strengthening mechanism, it can be apparently seen that the hardness of H930, H980, H1030 and H1080 was higher than H1130. Apparently, the recrystallization process of $\mathrm{H} 1130$ decreased the NF of LABs. Essentially, the LABs strengthening originated from the dislocation. The LABs with high MAs included a large number of dislocations. The NF of LABs can be used to distinguish the high dislocation density versus the low one, while the KAMA distribution indicates the degree of plastic strains, which is nearly associated with the dislocation density. Strictly speaking, the strengthening mechanism should be the strain strengthening. Figure $11 \mathrm{~b}$ illustrates the dislocation tangles in the as-deposited condition. From $980{ }^{\circ} \mathrm{C}$ to $1080{ }^{\circ} \mathrm{C}$, the microhardness held on $300 \mathrm{HV}$, since there is no obvious of the LABs and KAMAs distributions. After $1090{ }^{\circ} \mathrm{C}$, with the process of static recrystallization, the microhardness decreased gradually; when heated to $1130{ }^{\circ} \mathrm{C}$, the microhardness has dropped to $234.9 \mathrm{HV}, 73 \%$ of the as-deposited condition, which means the residual stress was released after the recrystallization process. To be noted, under the condition of $930^{\circ} \mathrm{C}$, the microhardness increased to $331 \mathrm{HV}$, because two factors: (1) The substructure was not eliminated. The strain strengthening also existed under this condition; (2) The forming of precipitate $\gamma^{\prime \prime}$, which is coherent with the matrix. The coherent strain induced on the interface between the matrix and sphase inhibited the movement of the dislocation, which increased the hardness of the sample. However, the coarse $\gamma^{\prime \prime}$ is prone to transform into the equilibrium phase $\delta$, which can't be serviced under high temperature. The microhardness of the as-rolled IN718 is 160-240 HV [36], which is the same level of the SLMed IN718 in solution heat treatment condition. The strain strenghtening generated from the printing process enhanced the microharness effectively due to the fast solidifaction and melting. 


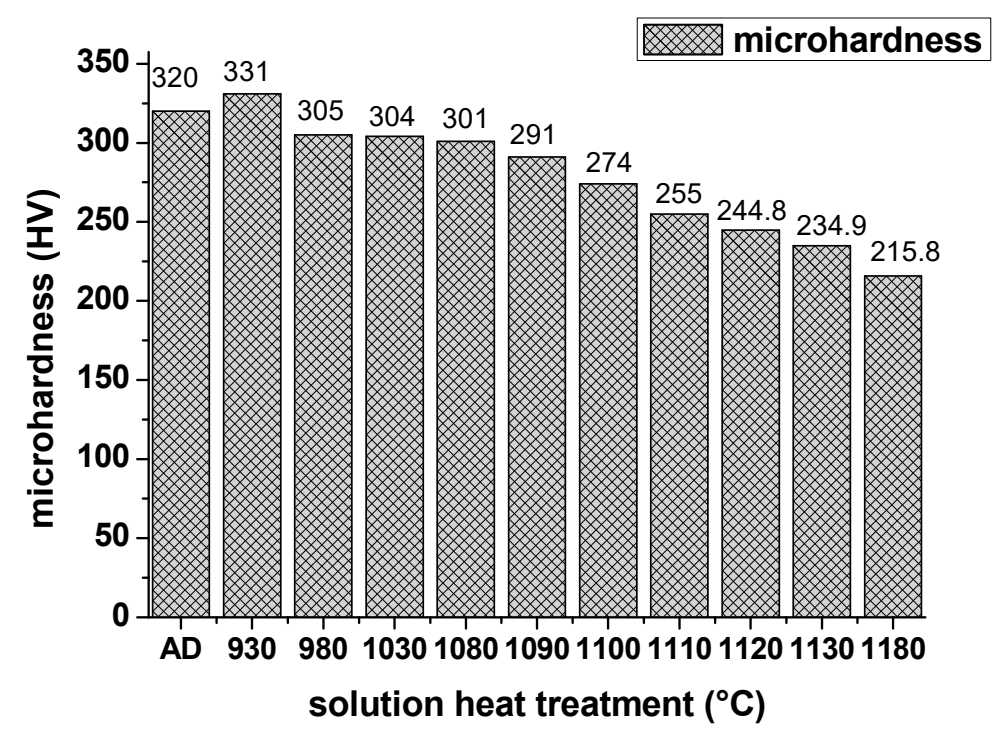

Figure 12. Microhardness of samples under the as-deposited condition and different solution heat treatment conditions.

\section{Conclusions}

The precipitates, grain features and hardness of IN718 alloy under the as-deposited and different solution heat treatment conditions were investigated in this article. The conclusions can be summarized as follows:

1. The precipitates of as-deposited IN718 are mainly Laves phases. After solution heat treatment under $930^{\circ} \mathrm{C} / \mathrm{h}$, the coarse $\gamma^{\prime \prime}$ and $\delta$ precipitate from the matrix. When heated above $980{ }^{\circ} \mathrm{C}$, most Laves phases dissolved into the matrix; only particle Laves phases and small bulk Laves phases can be seen along subgrain boundaries and grain boundaries, respectively. Even higher temperature can't dissolve all the Laves phases.

2. The aspect ratio of grains under as-deposited condition is 1.66 . From $980^{\circ} \mathrm{C}$ to $1080{ }^{\circ} \mathrm{C}$, the aspect ratio stayed around 1.6 , but dramatically dropped down to 1.03 when heated to $1130^{\circ} \mathrm{C}$. Static recrystallization process occurred at $1090^{\circ} \mathrm{C}$ and was completed rapidly at $1130^{\circ} \mathrm{C}$.

3. The LABs with high KAMAs kept stable during $980-1080^{\circ} \mathrm{C}$, and decreased hastily after $1090^{\circ} \mathrm{C}$. LABs disappeared completely at $1130^{\circ} \mathrm{C}$. The forming of annealing twins accompanied the recrystallization process. At the end of the recrystallization process, the NF of annealing twin boundaries reached $65 \%$.

4. The microhardness is affected by both the precipitates and grain features. The appearance of coarse $\gamma^{\prime \prime}$ can enhance the microhardness due to the coherent strain strengthening at $930{ }^{\circ} \mathrm{C}$. Substructure strengthening holds on from $980-1080^{\circ} \mathrm{C}$; residual strain didn't disappear during this temperature interval.

Author Contributions: This paper reports part of the Ph.D. work of Y.C. prepared under the supervision of P.B.; Y.C. and F.L. designed and performed the experiments; P.B. and X.H. helped analyze the data and improve the experiments; Y.C. wrote the paper in the present form; P.B. and X.H. reviewed this paper; Y.G. did some data analysis.

Funding: This paper was supported by the National Natural Science Foundation of China (No.11672140 and No.11762014) and the postgraduate Innovation Founding Project of Inner Mongolia autonomous region. (No. B2018111928).

Conflicts of Interest: The authors declare no conflict of interest. 


\section{References}

1. Fu, S.H.; Dong, J.X.; Zhang, M.C. Alloy design and development of Inconel 718 type alloy. Mater. Sci. Eng. A 2009, 499, 215-220. [CrossRef]

2. Sundararaman, M.; Singh, J.B.; Mukhopadhyay, P. Estimation of order strengthening in Inconel 718 type alloys containing all $\gamma^{\prime \prime}$ precipitate variants. Scr. Metall. Mater. 1993, 29, 557-562. [CrossRef]

3. Zemin, W.; Kai, G.; Ming, G. The microstructure and mechanical properties of deposited-IN718 by selective laser melting. J. Alloy. Compd. 1993, 513, 518-523.

4. Ian, G.; David, R.; Brent, S. Additive Manufacturing Technologies; Springer: New York, NY, USA, 2015.

5. Olga, I.; Christopher, W.; Thomas, C. Additive manufacturing (AM) and nanotechnology: Promises and challenges. Rapid Prototyp. J. 2013, 19, 353-364.

6. Haniyeh, F.; Mehrnaz, S.; Allan, R.; Dyuti, S.; Paola, R.; Vlad, P.; Ehsan, T. A critical review of powder-based additive manufacturing of ferrous alloys: Process parameters, microstructure and mechanical properties. Mater. Des. 2018, 144, 98-128.

7. Zhang, Y. Investigation on the optimized heat treatment procedure for laser fabricated IN718 alloy. Opt. Laser Technol. 2017, 97, 172-179. [CrossRef]

8. Xing, L.; Shi, J.J.; Wang, C.H. Effect of heat treatment on microstructure evolution of Inconel 718 alloy fabricated by selective laser melting. J. Alloy. Compd. 2018, 764, 639-649.

9. Song, Y.S.; Gao, W.F.; Wang, C. Effect of heat treatment technology on microstructure, mechanical property and corrosion resistance of nickel-base alloy Inconel 718. J. Mater. Eng. 2012, 2, 37-42.

10. Zhang, D.; Niu, W.; Cao, X. Effect of standard heat treatment on the microstructure and mechanical properties of selective laser melting manufactured Inconel 718 superalloy. Mater. Sci. Eng. A 2015, 644, 32-40. [CrossRef]

11. Pande, C.S.; Rath, B.B.; Imam, M.A. Effect of annealing twins on Hall-Petch relation in polycrystalline materials. Mater. Sci. Eng. A 2004, 367, 171-175. [CrossRef]

12. Yuan, Y.; Gu, Y.; Cui, C.; Osada, T.; Yokokawa, T.; Harada, H. A novel strategy for the design of advanced engineering alloys-strengthening turbine disk superalloys via twinning structures. Adv. Eng. Mater. 2011, 13, 296-300. [CrossRef]

13. Yuan, Y.; Gu, Y.F.; Osada, T.; Zhong, Z.H.; Yokokawa, T.; Harada, H. A new method to strengthen turbine disc superalloys at service temperatures. Scr. Mater. 2012, 66, 884-889. [CrossRef]

14. Yu, C.; Pucun, B.; Fei, L.; Hou, X. Investigation on the precipitates of IN718 alloy fabricated by selective laser melting. Metals 2019, 9, 1128.

15. Chen, Y.; Guo, Y.; Xu, M. Study on the element segregation and Laves phase formation in the laser metal deposited IN718 superalloy by flat top laser and gaussian distribution laser. Mater. Sci. Eng. A 2019, 754, 339-347. [CrossRef]

16. Knorovsky, G.A.; Cieslak, M.J.; Headley, T.J. Inconel 718: A solidification diagram. Metall. Trans. A 1989, 20, 2149-2158. [CrossRef]

17. Sui, S.; Tan, H.; Chen, J. The influence of Laves phases on the room temperature tensile properties of Inconel 718 fabricated by powder feeding laser additive manufacturing. Acta Mater. 2019, 164, 413-427. [CrossRef]

18. Deng, D.; Peng, R.L.; Brodin, H. Microstructure and mechanical properties of Inconel 718 produced by selective laser melting: sample orientation dependence and effects of post heat treatments. Mater. Sci. Eng. A 2018, 713, 294-306. [CrossRef]

19. Cao, G.H.; Sun, T.Y.; Wang, C.H. Investigations of $\gamma^{\prime}, \gamma^{\prime \prime}$ and $\delta$ precipitates in heat-treated Inconel 718 alloy fabricated by selective laser melting. Mater. Charact. 2018, 136, 398-406. [CrossRef]

20. Le, Z.; Abhishek, M.; Brandon, M.; Kyu, C.; Yongho, S. Microstructure, precipitates and mechanical properties of powder bed fused inconel 718 before and after heat treatment. J. Mater. Sci. Technol. 2019, 35, 1153-1164.

21. Shi-Hong, Z.; Hai-Yan, Z.; Ming, C. Tensile deformation and fracture characteristics of delta-processed Inconel 718 alloy at elevated temperature. Mater. Sci. Eng. A 2011, 528, 6253-6258.

22. Chen, W.; Chaturvedi, M.C.; Richards, N.L. Effect of boron segregation at grain boundaries on heat-affected zone cracking in wrought Inconel 718. Metall. Mater. Trans. A 2001, 32, 931-939. [CrossRef]

23. Antonsson, T.; Fredriksson, H. The effect of cooling rate on the solidification of Inconel 718. Metall. Mater. Trans. A 2005, 36, 85-96. [CrossRef]

24. Pottlacher, G.; Hosaeus, H.; Kaschnitz, E. Thermophysical properties of solid and liquid Inconel 718 Alloy. Scand. J. Metall. 2002, 31, 161-168. [CrossRef] 
25. Liu, F.; Lin, X.; Yang, G. Microstructure and residual stress of laser rapid formed Inconel 718 nickel-base superalloy. Opt. Laser Technol. 2011, 43, 208-213. [CrossRef]

26. Liu, H.; Shui, J.; Cai, T. Microstructural evolution and hardness response in the laser beam welded joints of pure titanium during recrystallization and grain growth. Mater. Charact. 2018, 145, 87-95. [CrossRef]

27. Sirous, A.; Ehab, E.-D.; Surya, R.K.; Roger, D.D. Strain hardening regimes and microstructural evolution during large strain compression of low stacking fault energy fcc alloys that form deformation twins. Metall. Mater. Trans. A 1997, 28, 1781-1795.

28. Dingley, D. Progressive steps in the development of electron backscatter diffraction and orientation imaging microscopy. J. Microsc. 2004, 213, 214-224. [CrossRef]

29. Zhang, T.; Collins, D.M.; Fionn, P.E.D.; Shollock, B.A. Crystal plasticity and high-resolution electron backscatter diffraction analysis of full-field polycrystal Ni superalloy strains and rotations under thermal loading. Acta Mater. 2014, 80, 25-38. [CrossRef]

30. Dziaszyk, S.; Payton, E.J.; Friedel, F. On the characterization of recrystallized fraction using electron backscatter diffraction: A direct comparison to local hardness in an IF steel using nanoindentation. Mater. Sci. Eng. A 2010, 527, 7854-7864. [CrossRef]

31. Bozzolo, N.; Jacomet, S.; Logé, R.E. Fast in-situ annealing stage coupled with EBSD: A suitable tool to observe quick recrystallization mechanisms. Mater. Charact. 2012, 70, 28-32. [CrossRef]

32. Chen, X.M.; Lin, Y.C.; Wu, F. EBSD study of grain growth behavior and annealing twin evolution after full recrystallization in a nickel-based superalloy. J. Alloy. Compd. 2017, 724, 198-207. [CrossRef]

33. Kumar, M.; Schwartz, A.J.; King, W.E. Microstructural evolution during grain boundary engineering of low to medium stacking fault energy fcc materials. Acta Mater. 2002, 50, 2599-2612. [CrossRef]

34. Mahajan, S.; Pande, C.; Imam, M. Formation of annealing twins in fcc crystals. Acta Mater. 1997, 45, $2633-2638$. [CrossRef]

35. Gleiter, H. The formation of annealing twins. Acta Metall. 1969, 17, 1421-1428. [CrossRef]

36. Davis, J.R. Nickel, Cobalt, and Their Alloys; ASM International: Chicago, IL, USA, 2000.

(C) 2020 by the authors. Licensee MDPI, Basel, Switzerland. This article is an open access article distributed under the terms and conditions of the Creative Commons Attribution (CC BY) license (http://creativecommons.org/licenses/by/4.0/). 